\title{
Tabuada da Velha: Um Jogo Educacional Sobre Adição e Subtração
}

\author{
Mychelline Souto Henrique ${ }^{1}$, Izabelly Soares de Morais ${ }^{1}$, Silvia Pereira de \\ Azevedo ${ }^{1}$, Vicente Férrer de Araújo Albuquerque ${ }^{2}$ \\ ${ }^{1}$ Centro de Informática - Universidade Federal de Pernambuco (PE) \\ CEP - 50.740-560 - Recife - Brasil \\ ${ }^{2}$ Departamento de Sistema da Informação - Faculdade \\ de tecnologia da Paraíba (PB) - João Pessoa - Brasil. \\ \{msh, ism, spas\}@cin.ufpe.br, 7.vincent@gmail.com
}

\begin{abstract}
Resumo. O Objeto de Aprendizagem (OA) Tabuada da Velha é um recurso pedagógico que tem como objetivo reforçar os conceitos das operações básicas da matemática, a saber: adição e subtração. O protótipo inicial do jogo é na versão Web, ele possui duas fases (uma para cada operação) com telas de dicas e instruções (em forma de animação). Ele é um jogo de tabuleiro que possui dois perfis (Alunos e Professores), o perfil professores apresenta os relatórios gerados, com as seguintes informações: quantidade de erros, acertos e vitórias (pontuação) dos jogadores. Portanto, o professor conseguirá obter o feedback do desempenho dos seus alunos e ele poderá trabalhar melhor os conteúdos, caso haja deficiência na aprendizagem.
\end{abstract}

\section{Cenário de Uso}

A constante evolução das Tecnologias de Informação e Comunicação (TICs) tem provocado mudanças de paradigmas na sociedade. Na educação as TICs vêm mostrando a viabilidade de um novo modelo de ensino e aprendizagem, através do desenvolvimento de práticas pedagógicas inovadoras. Estudos sobre a inserção de novos recursos metodológicos no ensino da matemática são oriundos das tentativas de reduzir as dificuldades e o desinteresse que os alunos apresentam em relação a disciplina.

De acordo com Vitti (1996), as dificuldades que os alunos apresentam na disciplina de matemática não é um fato novo. Isso pode ser comprovado através dos resultados obtidos por meio das avaliações realizadas pelo Ministério da Educação (MEC) junto aos alunos das escolas públicas (municipais e estaduais). Os resultados dessas avaliações apontam o baixo desempenho dos alunos, para este trabalho foram analisados os dados da Prova Brasil.

A Prova Brasil ${ }^{1}$ busca avaliar estudantes que estão matriculados no Ensino Fundamental II, em específico, os alunos que cursam o $5^{\circ}$ e $9^{\circ}$ ano (Fundamental II). Ela tem por objetivo estabelecer alguns critérios para avaliar os alunos nas disciplinas de português e matemática, sendo interesse deste trabalho apenas os dados da disciplina de matemática. A prova observa o desempenho do aluno através da sua familiaridade com conceitos básicos e com a interpretação de problemas matemáticos. É neste ponto que o

\footnotetext{
${ }^{1}$ http://portal.mec.gov.br/index.php?option=com_content\&view=article\&id=210\&Itemid=324
} 


\section{CBIE-LACLO 2015}

Anais dos Workshops do IV Congresso Brasileiro de Informática na Educação (CBIE 2015)

conceito básico sobre as operações da matemática (adição e subtração) é extremamente relevante.

A educação básica brasileira é constantemente avaliada pelo $\mathrm{SAEB}^{2}$ (Sistema de Avaliação da Educação Básica). Dentre os diversos tópicos pesquisados, em 2013 (dados mais atualizados da Prova Brasil), os dados mostram que no Brasil ${ }^{3} 35 \%$ dos alunos do $5^{\circ}$ ano, obtiveram o desempenho satisfatório e apenas $11 \%$ dos alunos do $9^{\mathrm{a}}$ ano alcançaram a média satisfatória. A métrica em relação ao aprendizado adequado tem como base estudos realizados por especialistas em educação, que juntos determinaram quatro níveis em uma escala de proficiência (insuficiente, básico, proficiente e avançado), a relação de pontos que cada nível possui se encontra na Escala SAEB. Os dados do Brasil apontam que em 2013, o percentual de alunos que atingiram o desempenho adequado no $5^{\circ}$ ano $(35 \%)$ subiu apenas $2 \%$ em relação a pesquisa realizada em 2011 (33\%), no $9^{\circ}$ ano o percentual em 2013 (11\%) diminuiu 1\% em relação a 2011 (12\%).

Portanto, percebe-se que os alunos do $5^{\circ}$ ano possuem um déficit de aprendizagem, que é reflexo dos problemas que não foram solucionados nas fases anteriores $\left(1^{\circ}\right.$ ao $4^{\circ}$ ano - Fundamental I). Essa realidade reforça a necessidade de buscar metodologias e ferramentas inovadoras para apoiar o ensino dos conteúdos da disciplina de matemática, principalmente nos anos iniciais do Ensino Fundamental I. Por este motivo, o OA proposto tem o intuito reforçar o ensino das operações básicas da matemática (adição e subtração), os alunos dos anos iniciais do Fundamental I serão os beneficiados.

\section{Desenvolvimento}

O processo de desenvolvimento do jogo Tabuada da velha foi guiado por adaptações da metodologia ágil (Scrum). O Scrum permite à equipe tratar e resolver problemas e entregar $o$ produto final no prazo estabelecido, enquanto mantém a eficácia, produtividade e qualidade (SCHWABER e SUTHERLAND, 2011). Essa metodologia foi escolhida, pois além dela proporcionar uma rápida resolução dos problemas que surgem no decorrer do desenvolvimento, o protótipo do jogo foi desenvolvido durante uma disciplina de Engenharia de software, ofertada pelo mestrado acadêmico do Centro de Informática (CIn) da Universidade Federal de Pernambuco (UFPE).

$\mathrm{O}$ processo de desenvolvimento aconteceu da seguinte forma: as sprints eram entregues a cada sete dias, todas as segundas-feiras um novo Sprint Backlog era entregue, independente se havia aula de Engenharia de Software. A reunião presencial acontecia nas segundas à tarde, durante a semana havia dois encontros remotos, ambos tinham duração de uma hora. A Figura 1 apresenta as doze sprints geradas e suas respectivas datas, o período de desenvolvimento aconteceu de 14 de abril á 14 de julho de 2014, contabilizando três meses. Os artefatos produzidos durante o desenvolvimento podem ser encontrados em um site ${ }^{4}$ que armazena todas as informações do protótipo do jogo Tabuada da Velha.

\footnotetext{
${ }^{2}$ http://provabrasil.inep.gov.br/

${ }^{3}$ http://www.qedu.org.br/brasil/proficiencia

4 http://mychelline.wix.com/jogueeaprenda
} 
CBIE-LACLO 2015

Anais dos Workshops do IV Congresso Brasileiro de Informática na Educação (CBIE 2015)

\begin{tabular}{|c|c|c|c|}
\hline $\begin{array}{l}\text { Sprint } 1 \text { (14-04-14) } \\
\text { Criação da ideia do } \\
\text { projeto e elaboração } \\
\text { do Site. }\end{array}$ & $\begin{array}{l}\text { Sprint } 5(19-05-14) \\
\text { Implementação de } \\
\text { novas funcionalidades } \\
\text { e hospedagem do } \\
\text { jogo no site usando o } \\
\text { Dropbox. }\end{array}$ & $\begin{array}{l}\text { Sprint } 9(16-06-14) \\
\text { Bugs corrigidos verificaçöes } \\
\text { da Sprint Review e novas } \\
\text { funcionalidades implemen- } \\
\text { tadas. }\end{array}$ & $\begin{array}{l}\text { Sprint } 12(07-07-14) \\
\text { Atualização de alguns } \\
\text { scripts PHP e melhora no } \\
\text { layout dos relatórios gerados } \\
\text { em HTML. Correção de }\end{array}$ \\
\hline & Sprint $6(26-05-14)$ & \multirow{5}{*}{$\begin{array}{l}\text { Sprint } 10 \text { (23-06-14) } \\
\text { Compra do dominio } \\
\text { (Wmuntabuadadavelhacom) e } \\
\text { alocação da versão do jogo } \\
\text { no servidor hostinger. } \\
\text { Integraça com o banco de } \\
\text { dados Mysql. } \\
\text { Sprint } 11(30-06-14) \\
\text { Implementação do banco } \\
\text { de dados que guardará } \\
\text { informaçōes dos usuários. } \\
\text { Implementação dos scripts } \\
\text { PHP para fazer a conexão } \\
\text { do jogo usando Ajax para } \\
\text { enviar os dados para o } \\
\text { servidor/banco de dados. }\end{array}$} & \multirow{5}{*}{$\begin{array}{l}\text { Sprint 13 (14-07-14) } \\
\text { Jogo com o sistema de } \\
\text { feedback para o professor, } \\
\text { com as funcionalidades de } \\
\text { relatório funcionando e } \\
\text { hospedado em um dominio } \\
\text { proprio. }\end{array}$} \\
\hline $\begin{array}{l}\text { Sprint } 2 \text { (28-04-14) } \\
\text { Requisitos levantados } \\
\text { e elaboração do DRS. }\end{array}$ & $\begin{array}{l}\text { Construção do mapa } \\
\text { conceitual } \\
\text { implementaçăo de } \\
\text { novos requisitos. }\end{array}$ & & \\
\hline Sprint $3(05-05-14)$ & $\frac{\text { Sprint } 7 \text { (02-06-14) }}{\text { Mudança de cenário. }}$ & & \\
\hline $\begin{array}{l}\text { Elaboraçãor de } \\
\text { artefatos (UC, mapa } \\
\text { de navegaçăo e task } \\
\text { board). }\end{array}$ & $\begin{array}{l}\text { Mudança de cenário, } \\
\text { novas funcionalidades } \\
\text { e telas do perfil profes- } \\
\text { sor implementadas. }\end{array}$ & & \\
\hline $\begin{array}{l}\text { Sprint } 4(12-05-14) \\
\text { Novas versōes dos } \\
\text { artefatos e mudanças } \\
\text { de alguns requisitos. }\end{array}$ & $\begin{array}{l}\text { Sprint } 8(09-06-14) \\
\text { Telas do perfil } \\
\text { professor } \\
\text { implementadas. }\end{array}$ & & \\
\hline
\end{tabular}

A Figura 1 - Sprints geradas no processo de desenvolvimento do protótipo Tabuada da Velha

As tecnologias utilizadas para desenvolver o protótipo Tabuada da velha foram:

- Construct 2: é uma engineer para desenvolvimento de jogos de código aberto, ele usa HTML5 na construção dos jogos, desta forma os jogos podem ser acessados e executados em navegadores. Ele foi criado pelo grupo Scirra ${ }^{5}$, que se aproveita do DirectX para criar seus jogos. O Construct 2 utiliza plugins para realizar conexões externas com banco de dados, a saber: AJAX.

- Linguagem: a linguagem utilizada pelo Construct 2 é baseada no estilo drag-anddrop, que utiliza um editor visual, a lógica é baseada em comportamento. Portanto, existe pouca codificação para desenvolver a parte lógica do jogo.

- Comunicação com Banco de dados: O plugin AJAX (acrônimo em língua inglesa de Asynchronous Javascript And XML) é carregado e renderizado pela página, utilizando recursos de scripts rodando pelo lado cliente, buscando e carregando dados em segundo plano, sem a necessidade de reload da página. O Construct usa o AJAX para trocar dados com qualquer outra plataforma Online, no projeto ele foi utilizado para se comunicar com os scripts PHP, que por sua vez se comunica com um banco de dados MySql para persistência das informações (erros, acertos e vitórias (chamamos de pontuação), esses dados são chamados nos relatórios que estão localizados no perfil professores).

- PHP: Essa linguagem é importante para tratar os dados enviados pelo Construct 2 para o banco de dados, fazendo também o resgate das informações solicitadas pelo Construct 2 e retornando para o mesmo.

$\overline{{ }^{5} \text { https://www.scirra.com/construct2 }}$ 


\section{CBIE-LACLO 2015}

Anais dos Workshops do IV Congresso Brasileiro de Informática na Educação (CBIE 2015)

\section{Apresentação do software}

O protótipo do jogo Tabuada da Velha $^{6}$ reforça o conhecimento das operações matemáticas de adição e subtração a partir de uma adaptação do Jogo da Velha. A versão inicial do jogo é Web, o que possibilita que ele seja combinado com Ambientes Virtuais de Aprendizagem (AVA), desta forma os professores podem gerenciar o desempenho dos seus alunos a qualquer momento, e os alunos podem reforçar o seu conhecimento dentro ou fora da sala de aula. Um vídeo com as principais funcionalidades pode ser visto em https://youtu.be/Ee8nfDl-6rI.

O jogo foi criado para atender a dois perfis: Alunos e Professores (ver Figura 2). Ele tem o propósito avaliativo, pois o perfil professores apresenta uma visão individual (Busca por nome), global (Todos os jogadores) e específica (TOP 10 - Os dez melhores alunos) dos alunos.

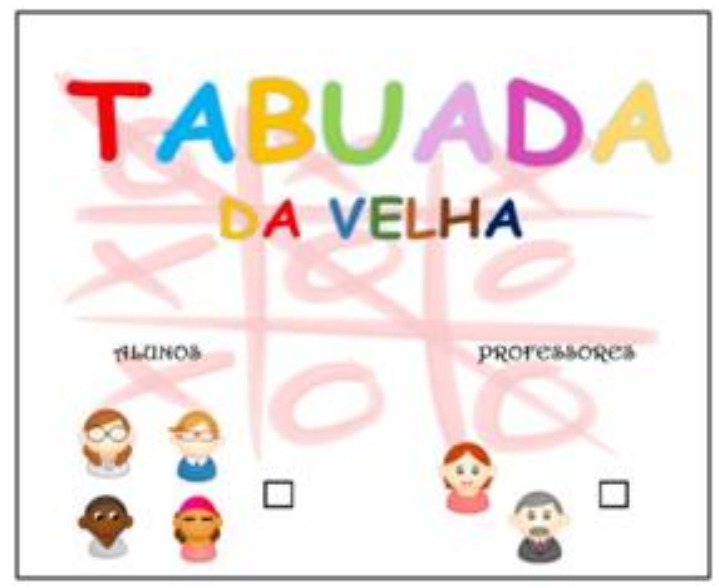

Figura 2 - Tela inicial com os perfis (alunos e professores)

A Figura 3A mostra o perfil alunos (é preciso que os nomes dos jogadores sejam informados para iniciar o jogo) e a Figura 3B apresenta o perfil professores (o login e senha são pré-determinados durante o desenvolvimento).

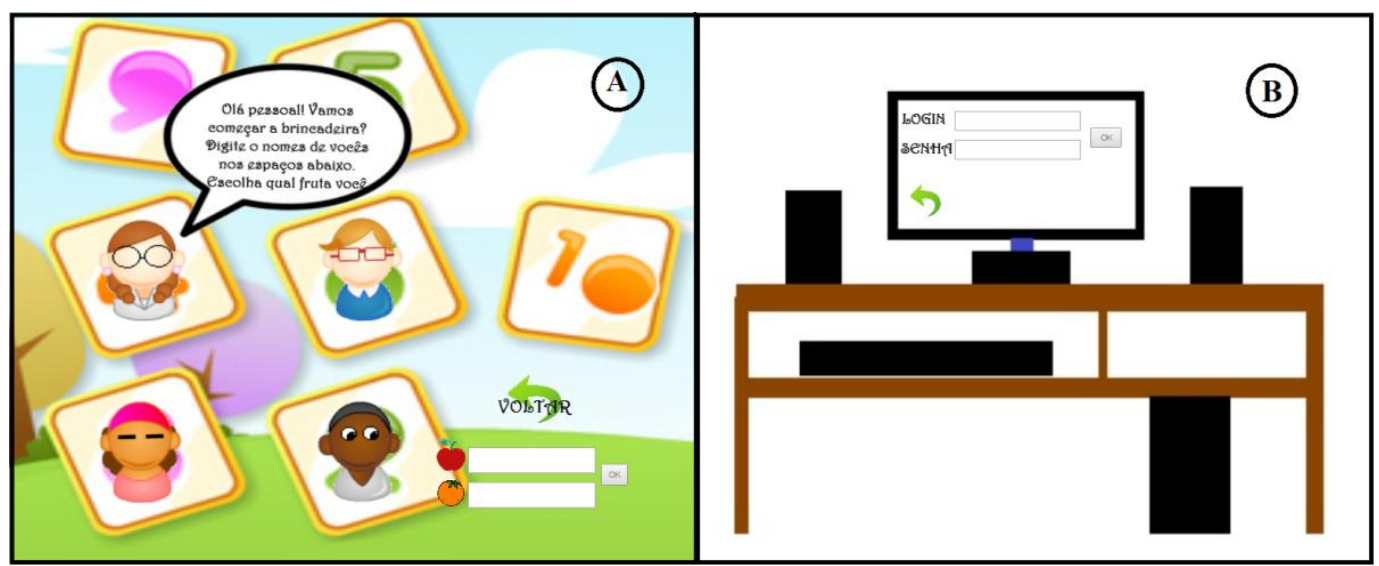

Figura 3 - (3A) Tela de cadastro do perfil alunos e (3B); Tela de autenticação do perfil professores

Foram utilizadas duas frutas para representar os jogadores (maçã e laranja), pois a intenção era desenvolver um ambiente lúdico, que fosse adequado para o público alvo do jogo (crianças entre 6 e 10 anos). As Figuras 4 e 5 mostram as telas onde acontecem as

${ }^{6}$ www.tabuadadavelha.com.br 


\section{CBIE-LACLO 2015}

Anais dos Workshops do IV Congresso Brasileiro de Informática na Educação (CBIE 2015)

jogadas. Além disso, as opções de navegabilidade (Dicas, Resetar e Voltar), a contabilização dos erros e acertos é vista durante a jogada pelos usuários.

Como já mencionado anteriormente, o Tabuada da Velha possui algumas características semelhantes ao Jogo da Velha tradicional. A regra geral é conseguir combinar três peças (frutas) iguais na horizontal, vertical ou diagonal. Porém, para que a (peça) fruta fique no tabuleiro é preciso que o resultado final equivalente ao cálculo da adição ou subtração, que está localizado dentro das peças, estejam corretos, senão a fruta volta para o seu lugar de origem e um erro é contabilizado, caso o resultado esteja correto, um acerto é contabilizado e a fruta fica no tabuleiro.

A maçã é representada pelo jogador 1 e a laranja é representada pelo jogador 2, os nomes dos jogadores são localizados no tabuleiro durante as jogadas, facilitando a identificação deles em relação as peças. Durante a jogada, o usuário pode resetar o jogo, porém, isso não apaga a contabilização (erros e acertos) das jogadas já realizadas, nesta opção, o que acontece é que as peças irão voltar aos seus locais de origem e temporariamente os erros e acertos ficam zerados.

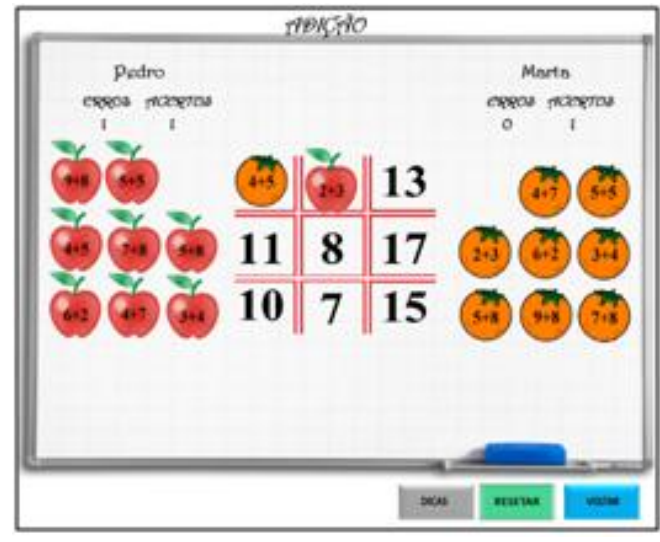

Figura 4- Tela do desafio da adição

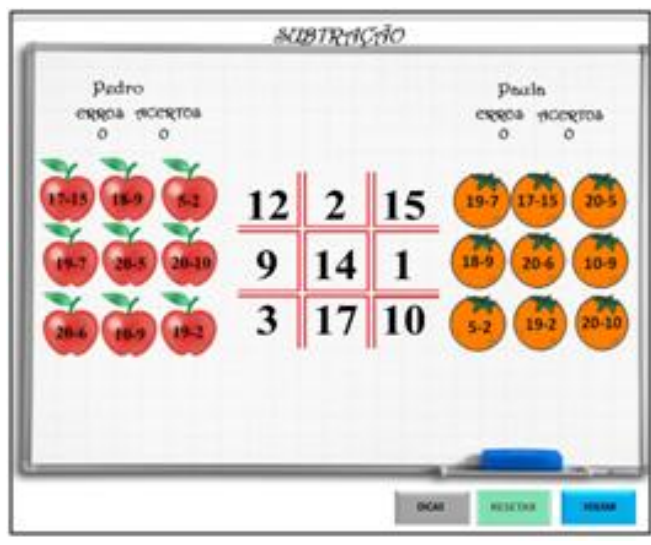

Figura 5- Tela do desafio da subtração

O menu "Dicas" direciona os usuários para a tela de dicas, na qual as operações básicas de adição e subtração são representadas em forma de animação (ver Figura 6A (adição) e 6B (subtração).

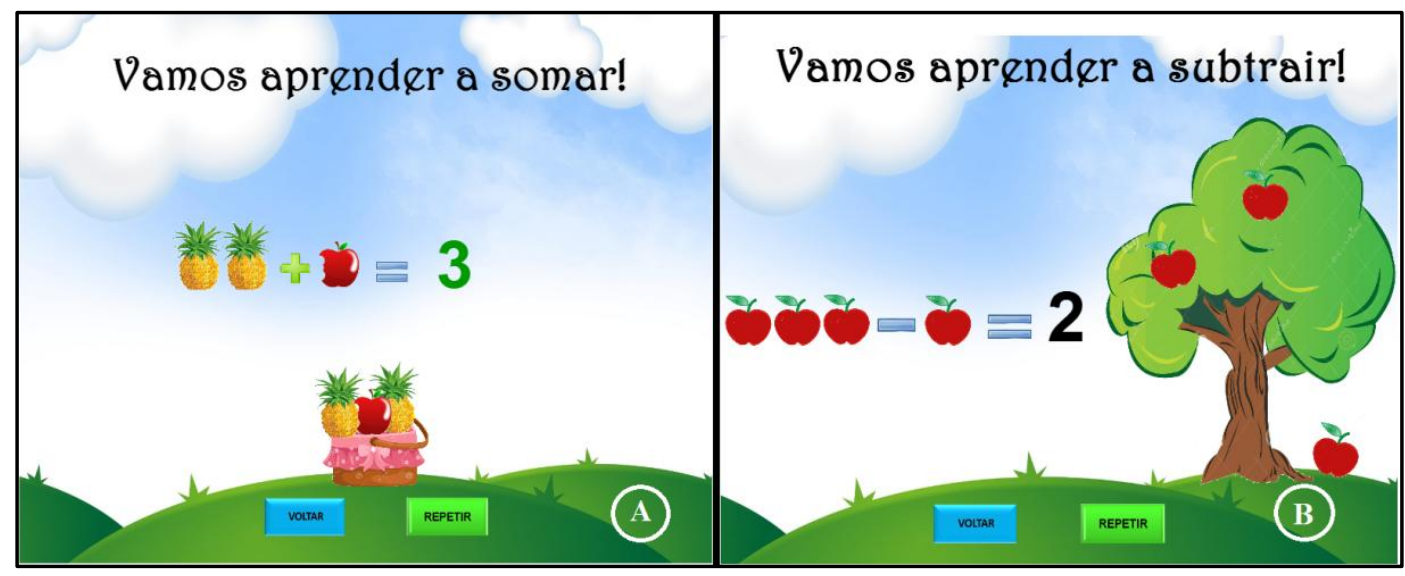

Figura 6 - Telas de dicas (subtração e adição)

Os relatórios com o desempenho dos alunos serão apresentados nas Figuras 7, 8 e 9. As informações disponibilizadas nos relatórios contêm erros, acertos e a pontuação (equivalente a vitória durante as jogadas) dos jogadores. 


\section{CBIE-LACLO 2015}

Anais dos Workshops do IV Congresso Brasileiro de Informática na Educação (CBIE 2015)

A Figura 7 apresenta a busca do aluno por nome, o professor pode realizar a busca digitando apenas uma letra ou o nome completo do aluno.

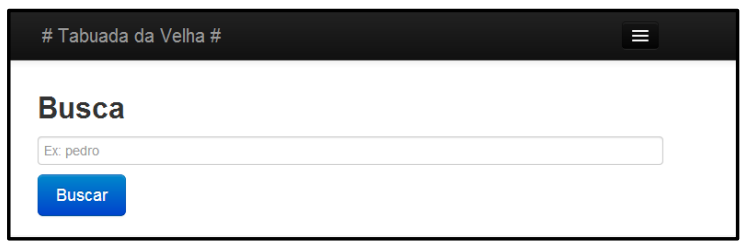

Figura 7 - Relatório da busca por nome

A Figura 8 apresenta o relatório de todos os alunos por ordem alfabética, nesse momento o professor pode ter uma visualização global sobre o desempenho dos seus alunos.

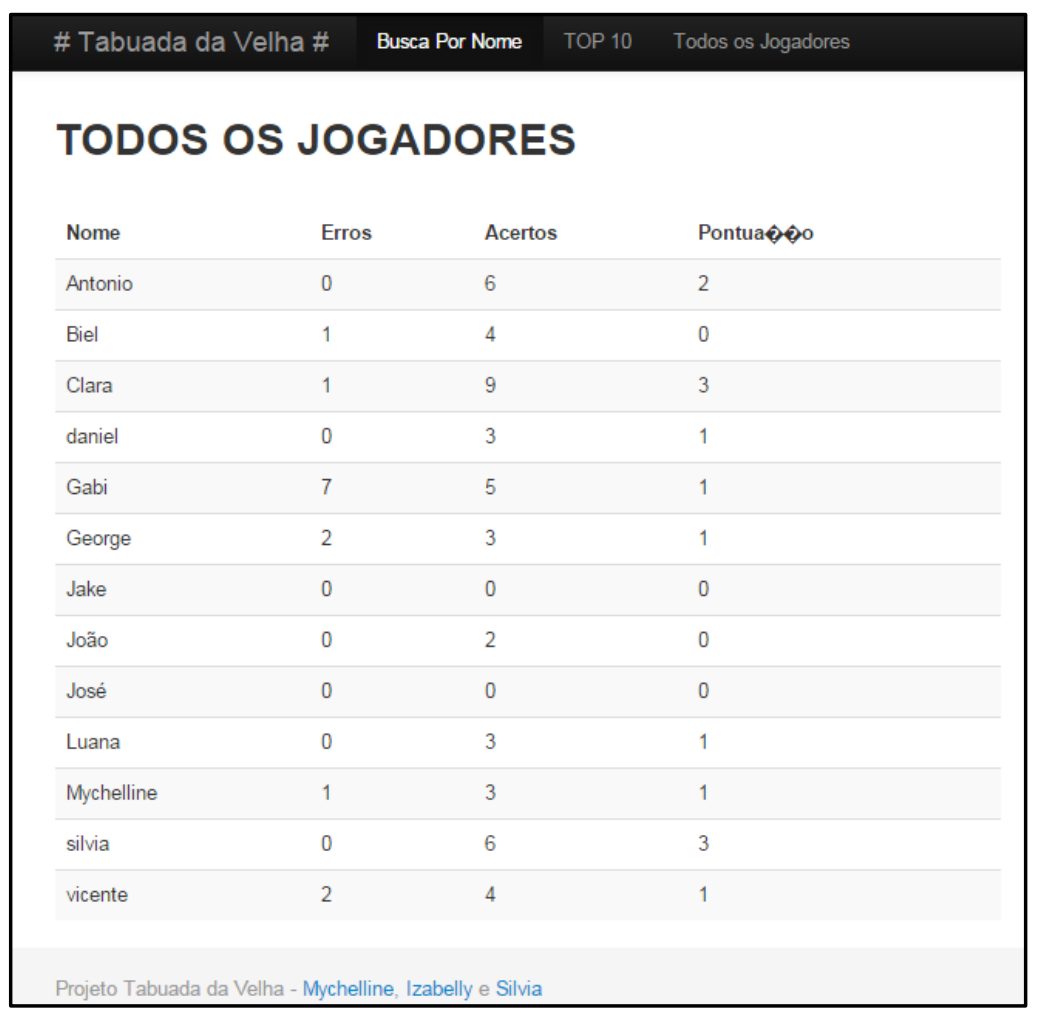

Figura 8. Relatório com as informações de todos os jogadores

A Figura 9 apresenta o relatório com os dez melhores jogadores, a classificação é feita pela pontuação, que equivale a vitória do jogador durante a jogada. 
CBIE-LACLO 2015

Anais dos Workshops do IV Congresso Brasileiro de Informática na Educação (CBIE 2015)

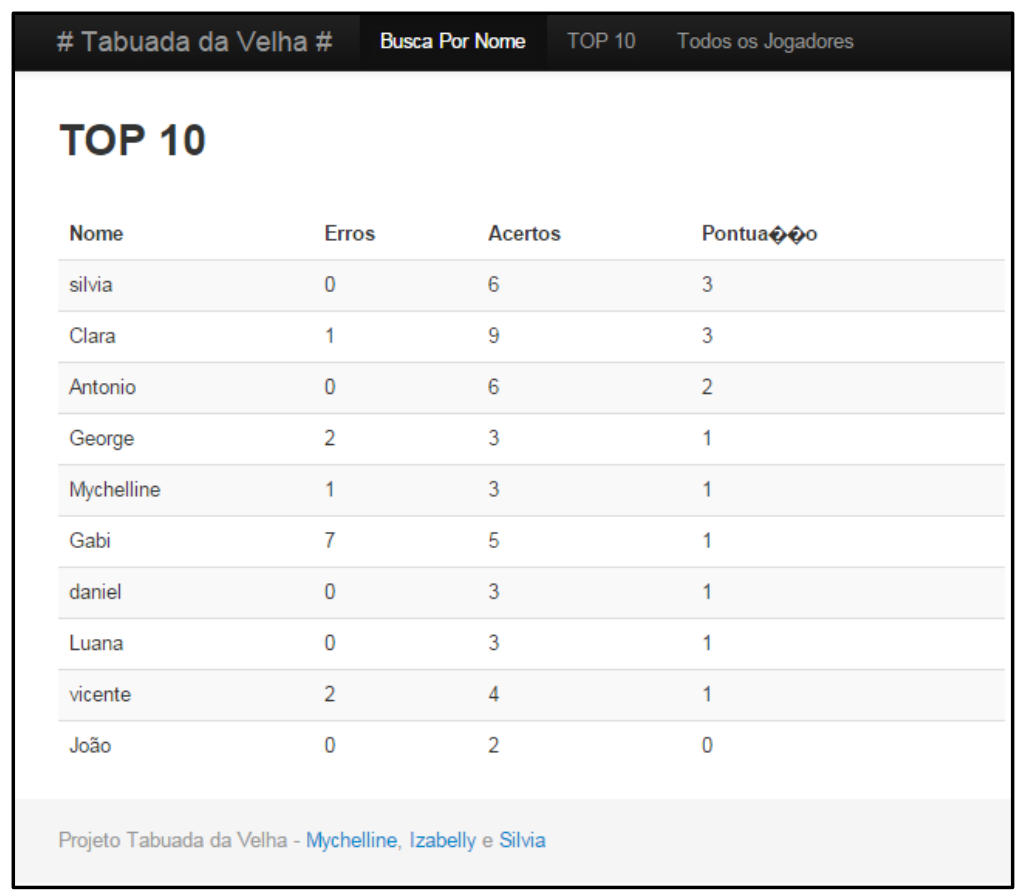

Figura 9. Relatório TOP 10 - Os dez melhores jogadores

\section{Considerações finais}

O desenvolvimento de um objeto de aprendizagem do tipo jogo educacional não é tão trivial como um software convencional. Algumas preocupações como: ludicidade, motivação, cenário, conteúdos abordados, é um grande desafio.

Vygotsky (1989) destaca a importância do professor apresentar os novos conceitos, tendo como base os conhecimentos prévios dos alunos e o contexto no qual os mesmos estão inseridos. Oliveira (1993), afirma que uma das formas de despertar o interesse pelo aprendizado de matemática, é através do uso de recursos que tornem as aulas mais lúdicas para os alunos. Ao brincar as crianças demonstram prazer para aprender. O autor afirma que, ensinar matemática é desenvolver no aluno o raciocínio lógico, estimulando-o na capacidade de resolver problemas.

Os jogos têm sido vistos como ferramentas que podem apoiar o professor no ensino de matemática bem como uma forma de despertar o interesse do aluno pelos conteúdos. De acordo com Brom (2011) os jogos digitais, como ferramentas educacionais, podem ajudar no desenvolvimento de habilidades cognitivas, como a resolução de problemas, o pensamento estratégico, a tomada de decisão, e pode apoiar uma compreensão mais profunda dos conteúdos abordados. Além de disponibilizar a criança, mais uma ferramenta para contribuir positivamente na fixação do conteúdo de operações matemáticas de soma e subtração.

O protótipo do jogo Tabuada da Velha é uma ferramenta que tem o propósito de auxiliar o aluno, levando em consideração seus conhecimentos prévios sobre as operações básicas da matemática (adição e subtração). Dessa forma, o OA é visto como uma atividade lúdica que envolve os alunos e apresenta desafios. Assim os alunos podem perceber que é possível aprender matemática de forma prazerosa e divertida. Ao optar por uma atividade direcionada ao ensino da matemática, o educador deve ter objetivos de aprendizagem bem definidos. A finalidade do uso dessas ferramentas diferenciadas é estimular a construção do conhecimento de conteúdos específicos. 


\section{CBIE-LACLO 2015}

Anais dos Workshops do IV Congresso Brasileiro de Informática na Educação (CBIE 2015)

Como projeto futuro pretende-se evoluir algumas funcionalidades do jogo, criar novas fases e atividades diferenciadas, para que ele possa ser homologado em escolas públicas e particulares. Pretende-se divulgar os resultados gerados com a pesquisa em eventos de engenharia de software e informática na educação, para que outros softwares educativos possam ser desenvolvidos.

\section{Referencias}

BROM, C., PREUSS, M. e KLEMENT, D. (2011) “Are educational computer microgames engaging and effective for knowledge acquisition at high-schools? A quasiexperimental study". Computers \& Education, 57(3), p.1971-1988.

OLIVEIRA, J. C. G.(1993) “A matemática no currículo escolar”, Bolema, n 9. Rio Claro. SCHWABER.K; SUTHERLAND. J. (2011) "The Definitive Guide to Scrum: The Rules of the Game", https://www.scrum.org/Portals/0/Documents/Scrum\%20Guides/Scrum_Guide.pdf.

VYGOTSKY, L. S. (1989). "Imaginación y creación en la edad infantil. La Habana: Editorial Pueblo y Educación".

VITTI, C. M. (1996). "Matemática com Prazer”. Piracicaba - SP: Unimep. 